\title{
Effect of oxygen flow rate on structural, electrical and optical properties of zinc aluminum oxide thin films deposited by DC magnetron sputtering *
}

\author{
(C) B. Rajesh Kumar ${ }^{1}$, B. Hymavathi ${ }^{2}$ \\ ${ }^{1}$ Department of Physics, Gandhi Institute of Technology and Management (GITAM), \\ Visakhapatnam - 530045 Andhra Pradesh, India \\ ${ }^{2}$ Department of Physics, Anil Neerukonda Institute of Technology and Sciences (Autonomous), Sangivalasa, \\ Visakhapatnam - 531162 Andhra Pradesh, India \\ E-mail: rajphyind@gmail.com
}

(Received April 4, 2018

Revised November 8, 2018

Accepted November 15, 2018)

Zinc Aluminum Oxide thin films were deposited on glass substrates by reactive DC magnetron sputtering method by varying oxygen flow rates from 1 to $4 \mathrm{sccm}$. Glancing angle $X$-ray diffraction patterns ofzinc aluminum oxide thin films exhibits $\left(\begin{array}{ll}0 & 0\end{array}\right)$ peak with $c$-plane preferentially oriented parallel to the substrate. The surface morphology and elemental analysis of the films was observed by field emission scanning electron microscopy attached with energy dispersive $X$-ray analysis spectroscopy. An average optical transmittance of $83-90 \%$ is obtained for the films deposited at various oxygen flow rates. The optical band gap of the films increases from 3.41 to $3.53 \mathrm{eV}$ with the increase of oxygen flow rate due to Burstein-Moss effect. The optical dispersion parameters such as dispersion energy $\left(E_{d}\right)$, oscillator energy $\left(E_{0}\right)$ and static refractive index $\left(n_{0}\right)$ were determined using the Wemple-DiDomenico (W-D) single oscillator model. The nonlinear optical parameters such as optical susceptibility $\left(\chi^{(1)}\right)$, third order nonlinear optical susceptibility $\left(\chi^{(3)}\right)$ and nonlinear refractive index $\left(n_{2}\right)$ were also determined.

DOI: $10.21883 /$ FTP.2019.04.47460.8887

* Полный текст статьи опубликован в переводной версии журнала „Физика и техника полупроводников“ - SEMICONDUCTORS (T. 53. Вып. 4). 